Revista da Sociedade Brasileira de Medicina Tropical

Journal of the Brazilian Society of Tropical Medicine

Vol.:52:e20190203: 2019

doi: 10.1590/0037-8682-0203-2019

\title{
Editorial
}

\section{Zika virus infection three years after the microcephaly outbreak: A meeting report}

\author{
Celina Maria Turchi Martelli[ ${ }^{[1]}$, Maria de Fatima Pessoa Militão de Albuquerque ${ }^{[1]}$, \\ Wayner Vieira de Souza ${ }^{[1]}$ and Sinval Pinto Brandão Filho[1]
}

[1]. Grupo de Pesquisa da Epidemia de Microcefalia (MERG), Consórcio Internacional ZikaPlan, Instituto Aggeu Magalhães, Fundação Oswaldo Cruz (Fiocruz), Recife, PE, Brasil

Are we prepared for the next Zika outbreak? Is congenital Zika virus infection still a threat, and if so, where? What was the attack rate of Zika infection in different regions? How can we improve the clinical and laboratory diagnosis of vectorborne infections in areas with simultaneous circulation of different flaviviruses? What are the implications of the current epidemiology of Zika virus (ZIKV) for vaccine development and future implementation? What are the intersections of the neurological-clinical findings in dengue, chikungunya, and Zika? Are the ongoing Zika consortia going to be sustainable in the years to follow? How are we going to provide sustainable health care for the affected children and their families? These important issues were the focus of the international meeting titled 'Zika virus: Three years after the microcephaly epidemic', held on March 12, 2019 at the Instituto Aggeu Magalhães (IAM)-Fiocruz Pernambuco, co-sponsored by the regional British Council as part of the "Ano Brasil-Reino Unido de Ciência e Inovação' (Brazil-UK Year of Science and Innovation).

This meeting followed the first international Zika Conference launched by IAM-Fiocruz-PE in March 2016, titled 'ABC of

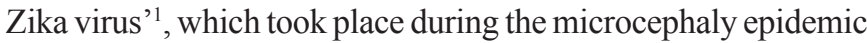
in the northeast of Brazil. This earlier congress was entirely dedicated to Zika- related adverse outcomes, and disclosed the lack of knowledge in almost all fields - from the epidemiology of Zika in urban areas, to the pathogenesis of congenital Zika syndrome, to the clinical features of the new congenital Zika syndrome associated with Zika infection ${ }^{1}$.

At the current meeting, held 3 years after, the opening address was given by Dr Annelies Wilder-Smith, coordinator of ZikaPLAN, on motivating issues around 'Perspectives of

Corresponding author: Sinval Pinto Brandão Filho.

e-mail: sinval@cpqam.fiocruz.br

Orcid: 0000-0003-3768-2810

Received 26 April 2019

Accepted 3 May 2019
ZikaPLAN Consortium and collaborative projects'2. Dr WilderSmith pointed out the strong mobilization of the worldwide scientific community regarding collaborative proposals and data-sharing initiatives, and the striking progress made in a short period of time. She also cited strong evidence based on cohort and case-control studies about the association between ZIKV infection and congenital ZIKV infection ${ }^{3,4}$, She also reflected on the ecological and individual-based findings excluding other risk factors hypothesized in the early epidemic days, such as vaccination or Pyriproxyfen use as a larvicide in selected regions ${ }^{5}$, and other ongoing studies developed by the Microcephaly Epidemic Research Group. She also pointed out several controversial issues about Zika vaccine production and its implementation in the current epidemiological scenario of presumably low ZIKV circulation in the Americas. These latter points about vaccination generated great interest among participants.

Drs Suzannah Lant and Bhagtheshar Singh were among the invited international speakers from the University of Liverpool, United Kingdom, who spoke on Zika-associated neurological disease in the adult population. It is important to mention that Dr Lant is a neurologist and researcher who has been living in Brazil as part of the multilateral exchange training effort based at the Hospital da Restauração, a referral public hospital in Recife. Dr Singh is also a neurologist, with research activities at the University of Liverpool and in India. The speakers discussed projects and preliminary results that focused on characterizing the epidemiology, clinical features and immunopathogenesis of neurological diseases associated with mosquito-borne viruses (Zika, chikungunya, and dengue). The projects are being developed by the neurology sector of the Hospital da Restauração, to be expanded to other health units in the State of Pernambuco. A comprehensive case series of acute neurological diseases associated with ZIKV and other arbovirus infections, including a Guillain-Barré syndrome case series, will be published soon. An ongoing case-control study is being conducted to enhance understanding of the association between 
ZIKV and other arbovirus infections with neurological diseases. In addition, other projects being developed aim to understand whether certain features of the host immune response to Zika may be protective of or associated with neurological disease. Importantly, during the clinical studies it was possible to refine the diagnostic criteria of Zika-associated neurological disease, and to compare and validate diagnostic tests. It is noteworthy that the University of Liverpool and Fiocruz, Brazil began collaborating shortly after the ZIKV outbreak in Latin America (2015-2016). These projects were funded by the Medical Research Council, the National Institute for Health Research and FACEPE, and subsequently by the European Union as part of ZikaPLAN (Zika Preparedness Latin American Network)2.

A roundtable discussion including experts in diverse fields of knowledge - clinicians, public health professionals and researchers - provided interesting overviews about the main circulating arbovirus on a regional basis. Dr Lucia Brito, chief of the neurology department of the Hospital da Restauração, presented a comprehensive description of a large case-series of Guillain-Barre syndrome that occurred before the microcephaly outbreak in Pernambuco, Brazil. These data are invaluable for developing an etiological model for the adverse neurological outcomes of dengue, Zika and chikungunya. Networking between health professionals in a well-structured health care setting with national and international research centers could be considered a win-win situation. Health professionals and researchers working together make progress toward diagnosis, knowledge and control of disease progression, and treatment standards promoting better patient care.

Dr André Siqueira, a researcher based at the Instituto de Infectologia Evandro Chagas, Fiocruz, Rio de Janeiro gave a lecture entitled 'Challenges and opportunities in clinical research in chikungunya in a multicentric study'. The closing lecture by Dr Tereza Lyra gave an outstanding overview of the social impact on the families of children affected by Zika congenital disease in the regional socio-economic context. The lecture brought aspects of qualitative and quantitative methodology together to paint a picture of the impact of the disease on the health system, on society, and particularly among the families concerned. As expected, mothers were mainly responsible for taking care of the affected children, and approximately half of the families had low incomes ( 1 to 3 minimum wage). This was also a multicenter project, with interviews conducted in the northeast region (Recife, Pernambuco) and the southeast (Rio de Janeiro). Financial support came from the Medical Research Council, as the London School of Hygiene and Tropical Medicine's international counterpart in this network.
We acknowledge the participation of the Pan-American Health Organization; Ministry of Health; State of Health Secretariat and decision-makers' representatives. Several regional partners - the Microcephaly Epidemic Research Group, Federal University of Pernambuco, State University of Pernambuco, Fundação de Apoio a Pesquisa de Pernambuco, Instituto Materno Infantil de Pernambuco - and members of the community, among others, also contributed to the discussions. This seminar attracted the attention not only of the academic community (including postgraduate and graduate students) but also public health managers and several social organizations, such as Mães de Anjos and Pastoral da Saúde, and the press. Considering the large number of participants assembled at this meeting and their interest, we may express that Zika and other arboviruses are perceived as a public health threat not only by the scientific community, but also by the population and the media at large.

Of course, most of the questions initially posed in this Editorial are still to be answered, showing that sustainable research collaboration is warranted over the following years. We thank the invited lecturers for their fantastic presentations. We also thank all participants for sharing their insights, perceptions and interest in the progress made by the scientific community. Our special thanks go to Graham Tidey of the British Council in Recife for supporting this event.

\section{REFERENCES}

1. França RFO, Neves MHL, Ayres CFJ, Melo-Neto OP, Filho SPB. First International Workshop on Zika Virus Held by Oswaldo Cruz Foundation FIOCRUZ in Northeast Brazil March 2016 - A Meeting Report. PLoS Negl Trop Dis [Internet]. 2016 [cited 2019 March 26];10(6):e0004760. Available from: https://www.arca.fiocruz.br/ handle/icict/19392.

2. ZikaPLAN. Zika Preparedness Latin America Network [Internet]. Sweden: ZikaPLAN; 2016 [updated 2019 March 6; cited 2019 March 26] Available from: https://zikaplan.tghn.org/.

3. Brasil P, Pereira JP, Moreira E, Nogueira RMR, Damasceno L, Wakimoto $\mathrm{M}$, et al. Zika virus infection in pregnant women in Rio de Janeiro. N Engl J Med. 2016;375(24):2321-34.

4. Araújo TVB, Ximenes RAA, Miranda-Filho DB, Souza WV, Montarroyos UR, Melo APL, et al. Association between microcephaly, Zika virus infection, and other risk factors in Brazil: final report of a case-control study. Lancet Infect Dis. 2018;18(3):328-36.

5. Albuquerque MFPM, Souza WV, Mendes AC, Lyra TM, Ximenes RAA, Araújo TVB et al. Pyriproxyfen and the microcephaly epidemic in Brazil -an ecological approach to explore the hypothesis of their association. Mem Inst Oswaldo Cruz. 2016;111(12):774-6. 